\title{
Alcohol use in New York after the terrorist attacks: A study of the effects of psychological trauma on drinking behavior
}

\author{
Joseph A. Boscarino a,b,*, Richard E. Adams ${ }^{a}$, Sandro Galea ${ }^{\mathrm{c}, \mathrm{d}}$ \\ ${ }^{\mathrm{a}}$ Division of Health and Science Policy, Room 552, The New York Academy of Medicine, 1216 Fifth Avenue, New York, \\ NY 10029-5293, United States \\ ${ }^{\mathrm{b}}$ Departments of Pediatrics and General Internal Medicine, Mount Sinai School of Medicine, New York, NY, United States \\ ${ }^{\mathrm{c}}$ Center for Urban Epidemiologic Studies, The New York Academy of Medicine, New York, NY, United States \\ ${ }^{\mathrm{d}}$ Division of Epidemiology, Columbia University, Mailman School of Public Health, New York, NY, United States
}

\begin{abstract}
Research has suggested that exposure to psychological trauma is associated with increased abuse of psychoactive substances, particularly alcohol. To assess this, we analyzed alcohol consumption, binge drinking, and alcohol dependence among a random sample of 1681 New York City adults 1 year and 2 years after the September 11 attacks. In multivariate models controlling for demographic factors, other stressor exposures, social psychological resources, and history of anti-social behavior, we found that greater exposure to the World Trade Center disaster (WTCD) was associated with greater alcohol consumption at 1 year and 2 years after this event. In addition, our analyses also indicated that exposure to the WTCD was associated with binge drinking at 1 year after but not 2 years after this event. Alcohol dependence, assessed as present in either year 1 or year 2, also was positively associated with greater WTCD exposures. Posttraumatic stress disorder was not associated with alcohol use, once WTCD exposure and other covariates were controlled. Our study suggests that exposure to psychological trauma may be associated with increases in problem drinking long after exposure and deserves further investigation.
\end{abstract}

(C) 2005 Elsevier Ltd. All rights reserved.

Keywords: Community disasters; Posttraumatic stress disorder; Alcohol abuse; Psychological distress; Survey research

\footnotetext{
* Corresponding author. Division of Health and Science Policy, Room 552, The New York Academy of Medicine, 1216 Fifth Avenue, New York, NY 10029-5293, United States. Tel.: +1 212419 3551; fax: +1 2128227369.

E-mail address: jboscarino@nyam.org (J.A. Boscarino).
} 


\section{Introduction}

Research has suggested increases in substance use among those recently exposed to community disasters (Grieger, Fullerton, \& Ursano 2003; Pfefferbaum \& Doughty, 2001; Stewart, 1996; Stewart, Mitchell, Wright, \& Loba, 2004; Vlahov et al., 2002; Vlahov, Galea, Ahern, Resnick, Boscarino et al., 2004). In addition, substance use has been a documented co-morbid factor accompanying physical and psychological problems following exposure to traumatic events (Boscarino, 1981; Grieger et al., 2003; Kessler Sonnega, Bromet, \& Hughes, 1995; Vlahov et al., 2002). These findings suggest that exposure to traumatic stressors might be a potential risk factor for substance abuse (Chilcoat \& Menard, 2003; Ouimette \& Brown, 2003). Furthermore, there is evidence to support a possible "self-medication" model in this association between substance abuse and traumatic stressor exposures (Chilcoat \& Menard, 2003). That is, exposure to psychological trauma may be related to substance abuse because these experiences often result in adverse psychological symptoms (e.g., hyper-arousal, re-experiencing trauma experiences), which victims may attempt to relieve through the anesthetizing effects of alcohol or drug use (Epstein, Sanders, Kilpatrick, \& Resnick, 1998; Stewart \& Conrod, 2003). Nevertheless, while studies of the association between substance use and exposure to psychological distress have a considerable history in behavioral research (Boscarino, 1981; Gottheil, Druley, Pashko, \& Weinstein, 1987; Linsky, Colby, \& Straus, 1991; Ouimette \& Brown, 2003), these findings have not been consistent. For example, while experimental studies tend to report links between alcohol use and stress reduction, community-based studies tend to show less consistent results (Gottheil et al., 1987). In addition, recent research suggests that this relationship is likely more complicated than originally conceptualized (Cooper, Russell, \& George, 1988). For example, it has been suggested that individual coping styles related to expectations about alcohol use mediated the link between alcohol use and coping with stressful events (Cooper et al., 1988). In particular, it was reported that stressors were predictive of both alcohol use and drinking problems among those who relied on avoidant emotional coping or those who held positive expectancies about the reinforcing effect of alcohol (Cooper, Russell, Skinner, Frone, \& Mudar, 1992). In contrast, stressors were negatively related among those who were low on these factors (Cooper et al., 1992).

In the present study, we examine the relationship between alcohol use within the context of the World Trade Center disaster (WTCD) on September 11, 2001. The WTCD was a unique, timebounded event in the history of psychiatric epidemiology. We hypothesized that the magnitude of this event had the potential to overwhelm existing social resources and psychological mechanisms and could have put many individuals at risk for substance abuse. Approximately 2800 persons died during this event, which was one of the largest death tolls of any disaster in the United States (Centers for Disease Control and Prevention, 2002). Many residents directly witnessed the attacks and had relatives or friends who died in the disaster. In addition, a large area of lower Manhattan's business district was destroyed, further exacerbating social and economic hardships in the area. The scope of the attacks and their impact on the local community suggested that these events might have significant long-term consequences. Indeed, early post-disaster research documented a high prevalence of psychological symptoms and disorders among residents of New York City (NYC), with $7.5 \%$ of those living south of 110 th Street in Manhattan having symptoms related to PTSD and $9.7 \%$ having symptoms related to depression 1 month after the attacks (Boscarino, Galea et al., 2004; Galea et al., 2002). These early post-disaster studies also 
documented the increased use of substances such as alcohol, cigarettes, and marijuana and linked these increases to psychological disorders (Vlahov et al., 2002; Vlahov, Galea, Ahern, Resnick, Boscarino et al., 2004, Vlahov, Galea, Ahern, Resnick, Kilpatrick, 2004). In the US, alcohol is readily available, most adults consume alcohol annually, and this substance is by far the most widely abused (National Institute on Alcohol Abuse and Alcoholism, 2000). Given these factors, we expected to see an association between trauma exposures and alcohol abuse in our study up to 2 years after the attacks.

Although level of event exposures and disaster-related losses are commonly associated with the psychological impact of traumatic events (Bland, O’Leary, Farinaro, Jossa, \& Trevisan, 1996; Caldera, Palma, Penayo, \& Kullgren, 2001; Mecocci et al., 2000), there are other factors also involved. For example, research suggests that increased vulnerability often occurs among those with a history of mental health disorders, child abuse, or a history of previous traumas (Breslau, Chilcoat, Kessler, \& Davis, 1999; Shalev, 1996; Yehuda, 1999). Furthermore, demographic factors are known to be associated with these experiences (Kessler, Sonnega, Bromet, \& Hughes, 1995; Tierney, 2000). In addition, research has consistently identified the role of social support among those exposed to traumatic stress, both in terms of protecting individuals from the psychological consequences of these events (Ursano, Grieger, \& McCarroll, 1996), and in terms of influencing effective treatment (Boscarino, 1995; van der Kolk, McFarlane, \& van der Hart, 1996). In summary, the degree of exposure, social factors, individual history, and other factors are believed to play a significant role in determining the impact of traumatic stressors and should be considered in evaluation efforts (Boscarino, 1995, 2000).

Within this context, the current study assesses the effects of exposure to psychological trauma in New York City on alcohol use among a random population sample of 1681 adults. Based on previous research, we hypothesized that exposure to WTCD-related traumatic events was related to both alcohol consumption and misuse up to 2 years after the WTCD, independent of other risk factors, such as demographic characteristics, history of traumatic exposures, stressful life events, and psychological or social resources. To our knowledge, given our sample and the number of risk factors examined, this analysis has not been previously undertaken. To guide our analytical approach, we used a general stress process model (Adams \& Boscarino, 2005; Pearlin, 1989; Thoits, 1995). This model suggests that individuals subjected to challenged environments often respond physiologically through alterations in neuroendocrine and hormone functions (Boscarino, 1996, 1997, 2004), psychologically, usually through alterations in cognitive functioning (Keane, Zimering, \& Caddell, 1985; Thoits, 1995), and behaviorally, usually through physical responses such as changes in sleep behavior, use of psychoactive substances, or through caloric intake (Boscarino, 2004), as well as through help-seeking behaviors, such as accessing available social support (Adams \& Boscarino, 2005; Pearlin, 1989; Thoits, 1995). Most investigators tend to define alcohol use as an avoidant coping strategy, which usually is thought to be ineffective in reducing stress or its adverse psychological consequences (Adams \& Boscarino, 2005). Serious environmental challenges that result in significant biological, psychological, or behavioral alterations are typically defined as stressful and referred to as "stressor events" (Adams \& Boscarino, 2005; Pearlin, 1989; Thoits, 1995). The consequence of exposure to these aversive stimuli can be psychological and physical distress, often involving depression, anxiety, and other negative psychological states (Adams et al., 2002; Boscarino, 2004; Bromet, Gluzman, Schwartz, \& Goldgaber, 2002; Norris, Friedman, \& Watson, 2002; Thoits, 1995), as well as the concomitant 
physiological, psychological, and behavioral alterations noted in an effort to adapt to these adverse conditions (Boscarino, 2004).

\section{Data and methods}

The data for the present study come from a 2-wave panel study of English or Spanish speaking adults living in NYC on the day of the WTCD and on the day of their interview. For the baseline survey (W1), we conducted a telephone survey 1 year after the attacks, using random-digit dialing. When interviewers reached a person at a residential telephone number, they obtained verbal consent and then ascertained the area of residence. If more than one eligible adult lived in the household, interviewers selected one based on the person with the most recent birthday. As part of the overall study, we over-sampled residents who reported receiving any mental health treatment in the year after the attacks. The population was also stratified by the $5 \mathrm{NYC}$ boroughs and sampled proportionately. Questionnaires were translated into Spanish and then back-translated by bilingual Americans to ensure the linguistic and cultural appropriateness of survey items. Interviews for W1 occurred between October and December 2002. For the follow-up survey (W2), we attempted to re-interview all W1 participants 1 year later (i.e., 2 years after the WTCD). All W2 interviews occurred between October 2003 and February 2004. The procedures were the same for both waves. Trained interviewers using a computer-assisted telephone interviewing system conducted the interviews. The interviewers were supervised and monitored by the survey contractor in collaboration with the investigative staff. A protocol was in place to provide mental health assistance to participants who required psychiatric counseling. The mean duration of the interviews was $45 \mathrm{~min}$ for $\mathrm{W} 1$ and $35 \mathrm{~min}$ for W2. The Institutional Review Board of The New York Academy of Medicine reviewed and approved the study's protocols.

Overall, 2368 individuals completed the W1 survey and 1681 completed the W2 survey. Approximately, 7\% of the interviews were conducted in Spanish for W1 and 5\% for W2. Using industry standards (American Association for Public Opinion Research, 2000), as we reported elsewhere (Boscarino et al., 2004) our W1 cooperation rate was approximately 63\%. ${ }^{1}$ During our W2 follow-up, we were able to re-interview $71 \%$ of our $\mathrm{W} 1$ respondents. A sampling weight was developed for each wave to correct for potential selection bias related to the number of telephone numbers and persons per household, and for the over-sampling of treatment-seeking respondents. In addition, as discussed below, demographic weights also were used for W2 data in order adjust for slight differences in response rates by different demographic groups, as is common practice in panel surveys (Groves et al., 2004; Kessler, Little, \& Groves, 1995). With these weights, both waves could be treated as a random, representative sample of residents who were living in NYC on the day of the WTCD (Groves et al., 2004).

\footnotetext{
${ }^{1}$ The cooperation rate was composed of (1) completed interviews, (2) screen outs-respondents who were not living in New York City at the time of the interview, were not living in New York City on September 11, or did not speak English or Spanish, (3) quota out-respondents who were eligible to be interviewed but were a gender or lived in a borough where the required number of interviews had been completed, and (4) refusals (cooperation rate $=$ completed interviews[2369] + screen outs[4985]+quota outs[117]/completed interviews + screen outs + quota outs + refusals[4330]). Our response rate, which is based on completed interviews divided by all eligible phone numbers and refusals, was $37 \%$ (completed interviews 2368]/quota outs[117] + refusals[4330] + residential phone but not interviewed by end of data collection[1945]).
} 


\section{Alcohol use and problem drinking measures}

In our analyses, we focused on factors that would predict W1 and W2 alcohol use, which included measures of alcohol consumption, binge drinking, and alcohol dependence as our outcomes measures. Following the standard for assessing binge drinking (Allen \& Columbus, 1995; Naimi et al., 2003), in the survey we asked how many times in the past year the respondent had 6 or more alcoholic drinks on one occasion. We dummy coded the responses, with never or less than monthly (coded 0 ) compared to monthly or more often (coded 1). In the survey, we also inquired about the respondent's consumption of alcoholic beverages based on the CAGE criteria for alcohol dependence (Magruder-Habib, Stevens, \& Alling, 1993), a widely used and validated scale (King, 1986). Using these data we defined meeting criteria for alcohol dependence if respondents had 2 or more positive answers on the CAGE survey (e.g., criticized about drinking, drank first thing in the morning, etc.). Because relatively few respondents met the CAGE criterion in a 12-month period, we defined alcohol dependence as present if the respondent met the criterion in the 24 months between the WTCD event and the W2 follow-up interview, with not meeting the criterion defined as the reference group. Based on alcohol consumption, we calculated an increase in drinking measure, which was the difference between the number of drinks per day for W2 minus the number of drinks per day for W1. In order to make this increase clinically meaningful, we divided the sample into those who had an increase of 2 or more drinks per day (coded 1) versus those who had less than a 2-drink increase, no change, or a decrease in drinking (coded 0). Our alcohol consumption measure was based on the number of drinks per month, which was the combination of two survey questions. Respondents were first asked how many days in the past month they drank alcoholic beverages (range 0-30) and then asked how many drinks they had on the days that they drank. We multiplied the responses to these two questions to calculate the drinks per month. Since the distribution of this variable was positively skewed, we transformed it by adding a constant (one) to each of the values and then took the natural log of the resulting sum, which tends to produce a "log normal" distribution better suited for analysis (Boscarino, 1980). We also recoded those respondents with values above the 95 percentile down to the 95 percentile value. Both of these transformations had the effect of creating a variable with a distribution that better approximates a normal curve. Our final measure of alcohol use included the number of drinks per day the respondent had on days that he or she drank. Although this measure was somewhat skewed, it did not clearly violate linear assumptions and, thus, was left untransformed. For the alcohol variables discussed, respondents who indicated that they never drank alcohol were coded to the lowest value on the particular measure (i.e., no binge drinking, not meeting criteria for the CAGE, no increase in drinks per day, 0 drinks per month, and 0 drinks per day when drank).

\section{Predictor variables}

\subsection{Background demographic characteristics}

Our analyses contained demographic variables, including age, education, gender, marital status, race/ ethnicity, and income. Although the same predictor variables were used for all of the analyses, we coded some of them differently depending on whether the outcome variable was binary or continuous. For the three binary dependent variables (binge drinking, alcohol dependency, and increase drinks per day), age 
was coded into four categories, 18-29, 30-44, 45-64, and 65+, with 65+ as the reference category. Education, gender, and marital status were dummy coded, as non-college graduate versus college graduate, male versus female, and not married versus married (including living together), with noncollege graduate, male, and not married used as the reference category. Consistent with previous research (Ortega, Rosenheck, Alegria, \& Desai, 2000), race/ethnicity was self-identified in the following manner. First, the survey interviewer asked the respondent if he/she was of Spanish or Hispanic origin. We next queried the respondent about his/her race, which included White, Black or African American, Asian, Native Hawaiian or other Pacific Islander, American Indian or Alaska Native, or "some other race". Using the responses to these two questions, we classified all respondents as follows: non-Hispanic White, non-Hispanic Black or African American, Hispanic, and Other Race/No Race Given. NonHispanic White was used as the reference category. Income was coded into four categories, including less than $\$ 30,000, \$ 30,000-\$ 99,999, \$ 100,000$ or more, and income not reported. For the continuous outcome variables (drinks per month and drinks per day when drank), education, gender, marital status, and race/ethnicity were coded the same as for the binary outcomes. Age was entered into the equations as a continuous variable divided by 10 . Income was now coded as an ordinal variable (coded 1-7), with the mean value replacing missing data, which was less than 5\%. All of the demographic variables reflected W1 data, unless the data were missing (e.g., reported household income), in which case, the W2 data were substituted where possible.

\subsection{Stressors, risk factors, and social psychological resources}

Our analyses included three stressor variables and one measure of anti-social behavior that may have placed the individual at higher risk for drinking problems, and two social psychological resources that could have lower such risk. First, the W1 survey inquired about 14 possible events (yes, no) that the responded could have experienced during the WTC attacks. Since there was no a priori method of assessing the severity of any individual event, we decided that a summation of the events experienced was the best measure of this stressor. We summed the events into a WTCD exposure scale and coded them into low exposure ( $0-1$ event), moderate exposure (2-3 events), high exposure (4-5 events), and very high exposure (6+ events), with low exposure as the reference category. This measure has been described in detail elsewhere (Boscarino, Adams, \& Figley, 2004). Second, the negative life event scale (Freedy, Kilpatrick, \& Resnick, 1993), was the sum of eight experiences that the respondent could have had in the 12 months before the WTCD (e.g., divorce, death of spouse, problems at work). Based on an examination of the frequency distribution, we coded respondents into three groups (no life events, one life event, and two or more life events), with no life events used as the reference category. The third stress measure involved 10 lifetime traumatic events (Freedy et al., 1993), other than the WTCD, which could have happened to the respondent (e.g., forced sexual contact, being attacked with a weapon, being in a serious accident). As previously described (Boscarino, Adams et al., 2004), these items were summed and collapsed into four categories, including, no traumas, 1 trauma, 2-3 traumas, and 4 or more traumas, with no traumas coded as the reference category.

We also measured a history of anti-social behavior using two survey questions: self-reports of ever being homeless or ever being arrested. We dummy coded responses, so that a yes to either question indicated a history of anti-social behavior, with none being the reference group. For the continuous outcome variables, such as number of drinks per month, we entered WTCD exposure, trauma history, and negative life events as continuous variables. 
The social psychological resource variables were social support (Sherbourne \& Stewart, 1989) and self-esteem (Rosenberg, 1979), both of which were collected during the W1 survey. Social support (Cronbach's alpha=0.83) was the sum of four questions about emotional, informational, and instrumental support (e.g., Someone available to help you if you were confined to bed.). Based on an examination of the scale's frequency distribution, we coded respondents into approximately three equal size groups: low, moderate, and high social support. The second resource measure, self-esteem, was measured by the Rosenberg self-esteem scale (Rosenberg, 1979). The scale (Cronbach's alpha=0.73) was the sum of five items in the original scale (e.g., I certainly feel useless at times. On the whole, I am satisfied with myself.). Similar to our social support measure, we divided the self-esteem scale into three categories of approximately thirds to represent low, moderate, and high esteem. For these resource variables, low social support and low self-esteem, respectively, were the reference categories. These 2 predictor variables, however, were retained as continuous variables in analyses where drinks/month and drinks/day when drank were used as the continuous dependent variables. All of these stress/risk and resource measures were used and validated in other WTCD studies in New York City and discussed elsewhere (Boscarino, Adams et al., 2004, Boscarino, Figley et al., 2004, Boscarino, Galea et al., 2004; Galea et al., 2002).

A final independent variable in our study related meeting criteria for PTSD. This measure was based on the Diagnostic and Statistical Manual of Mental Disorders, Fourth Edition (DSM-IV; American Psychiatric Association, 1994). Our PTSD measure was specifically developed for telephone administration and used in previous national and WTCD surveys among over 15,000 respondents (Boscarino, Adams et al., 2004; Galea et al., 2003; Kilpatrick et al., 2003; Resnick, Kilpatrick, Dansky, Saunders, \& Best, 1993). To meet the PTSD criteria in our study, a person first had to be exposed to a traumatic event (Criteria A1) and then experience intense feelings of fear, helplessness, or horror (Criteria A2). Second, the person had to re-experience the event in one of five ways (Criteria B), avoid stimuli associated with the event in three of seven ways (Criteria $C$ ), and have increased arousal in two of five ways (Criteria D). Third, the symptoms for Criteria B, C, and D had to last one month or longer (Criteria E) and interfere with the person's social functioning (Criteria F). Our assessment involved 3 sets of experiences, including the WTCD, the most stressful traumatic event experienced ("other than the WTCD"), and any other traumatic event experienced. To have PTSD, the person had to meet the A through F criteria for one or more of these traumatic events. The Cronbach's alpha for the PTSD symptoms used in this scale was 0.90 (Boscarino, Galea et al., 2004). Data related to the reliability and validity of our PTSD scale suggest that this instrument can be used to diagnose PTSD in population surveys and have been described in detail elsewhere (Boscarino, Adams et al., 2004).

\section{Statistical analysis}

Our analytic strategy proceeded in several steps. First, we present descriptive statistics for the five outcome variables discussed. Then, we estimate a series of logistic and ordinary least-squares (OLS) regression equations. More specifically, using logistic regression, we regressed binge drinking, alcohol dependency, and 2+ drink/day increase in alcohol use, respectively, on the independent variables discussed. For number of drinks per month and number of drinks per day when drank, we follow the same steps, but instead used OLS regression. For all analyses, we use the survey estimation (svy) command set in Stata, version 7 (Stata Corporation, 2001), to generate frequency distributions, point 
estimates, odds ratios, and regression coefficients. This estimation procedure adjusts the data to take into account our sampling design, which included case weights to adjust for potentially over-representing persons in households with more telephone lines per adult, the treatment over-sample, and W2 nonresponse adjustment. All $p$-values presented are based on 2-tail tests.

\section{Results}

Changes in reported alcohol use from 1 year prior to the WTCD, to 2 years post-WTCD, revealed small and statistically nonsignificant, increases in pathological drinking behavior as measured by binge drinking and alcohol dependence (Table 1). About 14\% of the sample reported drinking 6 or more alcoholic beverages in one occasion at least once a month before the WTCD. That percentage increased slightly to $16 \% 1$ year post-WTCD and decreased slightly to $15 \% 2$ years post-disaster. The percentage of respondents meeting criteria for alcohol dependence ranged between $1.6 \%$ and $2.8 \%$. However, our results also show that there was a statistically significant increase in the amount of alcohol consumed during this period. Approximately, $12 \%$ of New Yorkers reported an increase of two or more drinks per day between $\mathrm{W} 1$ and $\mathrm{W} 2$. In addition, the mean number of drinks per month and drinks per day when drank both exhibited a significant increase post-WTCD and between W1 and W2.

Examination of our OLS model predicting drinks per month at W1 (i.e., year 1) (Table 2, column 2), suggests that college graduates, men, the unmarried, Whites, higher income persons, individuals with

Table 1

Alcohol use pre-WTCD, 1 year post-WTCD, and 2 years post-WTCD $(\mathrm{N}=1681)^{\mathrm{a}}$

\begin{tabular}{|c|c|c|c|c|}
\hline Drinking variable & $\begin{array}{l}1 \text { year prior to } \\
\text { WTCD, \% (n) }\end{array}$ & $\begin{array}{l}1 \text { year post- } \\
\text { WTCD, \% (n) }\end{array}$ & $\begin{array}{l}2 \text { years post- } \\
\text { WTCD, \% (n) }\end{array}$ & $\begin{array}{l}1 \text { year vs. } 2 \text { years post- } \\
\text { WTCD, McNemar } \chi^{2}(p)\end{array}$ \\
\hline \multicolumn{5}{|l|}{ Binge drinking past year } \\
\hline No & $85.6(1464)$ & $84.1(1423)$ & $85.1(1448)$ & \multirow[t]{2}{*}{$(p=\mathrm{ns})$} \\
\hline Yes & $14.4(217)$ & $15.9(258)$ & $14.9(233)$ & \\
\hline \multicolumn{5}{|l|}{ Alcohol dependence } \\
\hline No & $98.4(1653)$ & $97.2(1622)$ & $97.3(1625)$ & \multirow[t]{2}{*}{$(p=\mathrm{ns})$} \\
\hline Yes & $1.6(28)$ & $2.8(59)$ & $2.7(56)$ & \\
\hline \multicolumn{5}{|l|}{ Increase of $2+$ drinks/day ${ }^{\mathrm{b}}$} \\
\hline No & - & $93.7(1566)$ & $87.6(1485)$ & \multirow[t]{2}{*}{$(p<0.001)$} \\
\hline \multirow[t]{2}{*}{ Yes } & - & $6.3(115)$ & 12.4 (196) & \\
\hline & Mean & Mean & Mean & Paired 2-tailed $t$-test $(p)$ \\
\hline $\begin{array}{l}\text { Number of } \\
\text { drinks/month (log) }\end{array}$ & 0.90 & 0.97 & 1.18 & $(p<0.001)$ \\
\hline $\begin{array}{l}\text { Number of } \\
\text { drinks/day past month }\end{array}$ & 0.94 & 1.06 & 1.31 & $(p<0.001)$ \\
\hline
\end{tabular}

${ }^{a}$ All percentages are weighted and all $n$ 's are unweighted as discussed in Data and methods; WTCD=World Trade Center Disaster.

b Increased drinking for 1 year post-WTCD represents increased drinking since 1-year pre-WTCD; increased drinking for 2 years post-WTCD represents increased drinking since 1 -year post-WTCD. 
Table 2

Ordinary Least Squares (OLS) regressions predicting the number of drinks per month/per day $(N=1681)$

\begin{tabular}{|c|c|c|c|c|}
\hline \multirow[t]{2}{*}{ Independent variables $^{\mathrm{a}}$} & \multicolumn{2}{|c|}{ Number of drinks/month } & \multicolumn{2}{|c|}{ Number of drinks/day } \\
\hline & Year 1, b (S.E.) & Year 2, b (S.E.) & Year 1, b (S.E.) & Year 2, b (S.E.) \\
\hline Age (years in decades) & $-0.01(0.02)$ & $-0.02(0.03)$ & $-0.08(0.03)$ & $-0.11(0.05)^{*}$ \\
\hline College graduate & $0.31(0.08)^{* * *}$ & $0.28(0.09)^{* * *}$ & $0.13(0.12)$ & $-0.03(0.15)$ \\
\hline Female gender & $-0.48(0.08)^{* * *}$ & $-0.51(0.09)^{* * *}$ & $-0.66(0.11)^{* * *}$ & $-0.85(0.17)^{* * *}$ \\
\hline Married & $-0.20(0.07)^{* *}$ & $-0.13(0.08)$ & $0.20(0.11)$ & $-0.13(0.14)$ \\
\hline African-American & $-0.45(0.09)^{* * *}$ & $-0.44(0.10)^{* * *}$ & $-0.48(0.12)^{* * *}$ & $-0.30(0.18)$ \\
\hline Latino & $-0.29(0.10)^{* *}$ & $-0.28(0.11)^{* *}$ & $-0.02(0.18)$ & $-0.25(0.22)$ \\
\hline Other & $-0.39(0.14)^{* *}$ & $-0.56(0.15)^{* * *}$ & $-0.49(0.15)^{* * *}$ & $-0.69(0.17)^{* * *}$ \\
\hline Income & $0.08(0.02)^{* * *}$ & $0.07(0.02)^{* *}$ & $0.06(0.03)$ & $0.06(0.04)$ \\
\hline Exposure to WTCD & $0.06(0.02)^{* *}$ & $0.05(0.02)^{*}$ & $0.09(0.03)^{* *}$ & $0.05(0.04)$ \\
\hline W1 Negative life events past year & $-0.01(0.05)$ & $-0.04(0.05)$ & $-0.01(0.08)$ & $-0.11(0.08)$ \\
\hline Lifetime traumatic events & $-0.00(0.02)$ & $0.02(0.02)$ & $0.02(0.03)$ & $0.05(0.03)$ \\
\hline Antisocial behavior history & $0.52(0.12)^{* * *}$ & $0.34(0.13)^{*}$ & $0.65(0.19)^{* * *}$ & $0.22(0.23)$ \\
\hline W1 Social support & $0.02(0.01)^{*}$ & $0.00(0.01)$ & $0.03(0.02)^{*}$ & $0.02(0.02)$ \\
\hline W1 Self-esteem & $-0.01(0.01)$ & $0.01(0.02)$ & $-0.03(0.02)$ & $-0.02(0.03)$ \\
\hline W1 PTSD past year & $-0.11(0.13)$ & $-0.20(0.16)$ & $-0.08(0.24)$ & $-0.29(0.22)$ \\
\hline Constant & 0.87 & 1.06 & 1.50 & 2.18 \\
\hline$R^{2}$ & $0.17 * * *$ & $0.14 * * *$ & $0.13 * * *$ & $0.10 * * *$ \\
\hline
\end{tabular}

WTCD $=$ World Trade Center Disaster.

${ }^{\text {a }}$ For this regression, age (coded in decades), exposure to WTCD, negative life events, lifetime traumatic events, social support, and self-esteem, were coded as continuous variables and income as a 7-point (1-7) ordinal variable. All other variables shown were coded as dichotomous variables, with White used as the reference category for race/ethnicity. All data are weighted, as discussed in Data and methods.

greater exposure to WTCD events, those who had a history of antisocial behavior, and persons with higher social support consumed more alcohol per month, compared to the less educated, women, non-Whites, lower income persons, those experiencing fewer WTCD events, individuals who were more socially conforming, and those with lower social support. The W2 drinks per month analyses (i.e., year 2) (Table 2, column 3) showed similar results. That is, the more educated, males, Whites, those exposed to greater WTCD events, and persons with a history of antisocial behavior, had more drinks per month 2 years after the terrorist attacks, than those less educated, females, non-Whites, and those less exposed to WTCD events.

Regression results for W1 drinks per day (Table 2, column 4) suggested, again, that lower alcohol consumption was related to being female, being African American or other/no race, having experienced few WTCD events, reporting no antisocial behavior history, and having low social support. The model for W2 drinks per day (Table 2, column 5) had only three statistically significant associations: age, gender, and race. More specifically, older respondents, females, and those categorized as other/no racial group drank less than younger, male, or White respondents. Interestingly, none of the stress, risk, or social resource independent variables were statistically significant for W2 drinks per day.

For our model predicting W1 binge drinking (Table 3, column 3), younger persons, males, those with greater exposure to WTCD events, and those with a history of antisocial behavior, were more likely to be binge drinkers. These results were consistent for W2 binge drinking as well (Table 3). Specifically, younger respondents, males, Latinos, those with a history of antisocial behavior, and those with lower self-esteem were more likely to meet the criteria for binge drinking, compared to their older, non-Latino, non-anti-social, and higher self-esteem counterparts. 
Table 3

Logistic regression coefficients for binge drinking, alcohol dependence, and increased drinks per day $(N=1681)^{\mathrm{a}}$

\begin{tabular}{|c|c|c|c|c|c|c|c|c|c|}
\hline \multirow[t]{3}{*}{$\begin{array}{l}\text { Predictor } \\
\text { variables }\end{array}$} & \multirow{3}{*}{$\begin{array}{l}\text { Total } \\
\text { Year } 1 \\
\%(N)\end{array}$} & \multicolumn{4}{|c|}{ Binge Drinking } & \multirow{2}{*}{\multicolumn{2}{|c|}{$\begin{array}{l}\text { Alcohol Dependence } \\
\text { Past } 2 \text { years } \\
\text { Year } 2 \\
\end{array}$}} & \multirow{2}{*}{\multicolumn{2}{|c|}{$\begin{array}{l}\text { Increased } \\
\text { Drinks/Day } \\
\text { Year } 1-2 \\
\end{array}$}} \\
\hline & & \multicolumn{2}{|l|}{ Year 1} & \multicolumn{2}{|l|}{ Year 2} & & & & \\
\hline & & OR & $(95 \% \mathrm{CI})$ & OR & $(95 \% \mathrm{CI})$ & OR & $(95 \% \mathrm{CI})$ & OR & $(95 \% \mathrm{CI})$ \\
\hline \multicolumn{10}{|l|}{ Age } \\
\hline $18-29$ & $22.7(284)$ & $3.64 * *$ & $(1.6-8.3)$ & $3.25 * *$ & $(1.5-6.9)$ & 2.29 & $(0.7-7.4)$ & $2.31 *$ & $(1.1-5.1)$ \\
\hline $30-44$ & $32.9(596)$ & $3.31 * *$ & $(1.5-7.3)$ & $2.27 *$ & $(1.1-4.7)$ & 1.92 & $(0.6-5.9)$ & $2.08 *$ & $(1.0-4.2)$ \\
\hline $45-64$ & $32.5(589)$ & 1.55 & $(0.7-3.4)$ & 1.73 & $(0.8-3.5)$ & 1.78 & $(0.6-5.4)$ & 1.36 & $(0.7-2.8)$ \\
\hline $65+($ Reference $)$ & 11.9 (215) & 1.00 & & 1.00 & & 1.00 & & 1.00 & \\
\hline \multicolumn{10}{|l|}{ Education } \\
\hline $\begin{array}{l}\text { Non-college graduate } \\
\text { (Reference) }\end{array}$ & $58.3(906)$ & 1.00 & & 1.00 & & 1.00 & & 1.00 & \\
\hline College graduate & 41.7 (775) & 0.79 & $(0.5-1.2)$ & 0.92 & $(0.6-1.4)$ & $2.10^{*}$ & $(1.1-3.9)$ & 1.01 & $(0.6-1.6)$ \\
\hline \multicolumn{10}{|l|}{ Gender } \\
\hline Male (Reference) & $46.2(693)$ & 1.00 & & 1.00 & & 1.00 & & 1.00 & \\
\hline Female & $53.8(988)$ & $0.37 * * *$ & $(0.3-0.5)$ & $0.31^{* * *}$ & $(0.2-0.5)$ & $0.35^{* * *}$ & $(0.2-0.6)$ & $0.52 * *$ & $(0.3-0.8)$ \\
\hline \multicolumn{10}{|l|}{ Marital status } \\
\hline $\begin{array}{l}\text { Not married } \\
\quad \text { (Reference) }\end{array}$ & 49.7 (972) & 1.00 & & 1.00 & & 1.00 & & 1.00 & \\
\hline Married & $50.3(709)$ & 0.89 & $(0.6-1.3)$ & 0.97 & $(0.7-1.4)$ & 0.58 & $(0.3-1.1)$ & 0.90 & $(0.6-1.4)$ \\
\hline \multicolumn{10}{|l|}{ Race } \\
\hline White (Reference) & $43.0(782)$ & 1.00 & & 1.00 & & 1.00 & & 1.00 & \\
\hline African American & $26.0(422)$ & 0.72 & $(0.4-1.2)$ & 0.71 & $(0.4-1.2)$ & 2.05 & $(1.0-4.3)$ & 1.42 & $(0.8-2.4)$ \\
\hline Latino & $24.1(367)$ & 1.19 & $(0.8-1.9)$ & $1.63^{*}$ & $(1.0-2.6)$ & $2.21 *$ & $(1.0-4.8)$ & $2.47 * * *$ & $(1.4-4.2)$ \\
\hline Other & $7.0(110)$ & 1.04 & $(0.5-2.2)$ & 0.93 & $(0.4-2.0)$ & 1.47 & $(0.5-4.8)$ & 0.27 & $(0.1-1.1)$ \\
\hline \multicolumn{10}{|l|}{ Income } \\
\hline$<\$ 30,000$ (Reference) & $33.8(599)$ & 1.00 & & 1.00 & & 1.00 & & 1.00 & \\
\hline $30,000-\$ 99,999$ & $46.5(782)$ & 1.12 & $(0.7-1.7)$ & 0.83 & $(0.5-1.3)$ & 0.75 & $(0.4-1.5)$ & 1.01 & $(0.6-1.6)$ \\
\hline$\$ 100,000+$ & $16.1(247)$ & 0.96 & $(0.5-1.8)$ & 0.75 & $(0.4-1.5)$ & 0.43 & $(0.2-1.1)$ & 0.90 & $(0.4-1.9)$ \\
\hline Not reported & $3.6(53)$ & 1.36 & $(0.5-4.6)$ & 0.72 & $(0.2-2.2)$ & 1.99 & $(0.6-7.1)$ & 0.83 & $(0.3-2.8)$ \\
\hline \multicolumn{10}{|l|}{ Exposure to WTCD } \\
\hline $\begin{array}{l}\text { Low ( } 0-1 \text { events) } \\
\text { (Reference) }\end{array}$ & $26.7(362)$ & 1.00 & & 1.00 & & 1.00 & & 1.00 & \\
\hline Moderate ( $2-3$ events) & 43.9 (719) & 1.63 & $(1.0-2.8)$ & 1.50 & $(0.9-2.5)$ & 1.53 & $(0.7-3.3)$ & 1.12 & $(0.7-1.8)$ \\
\hline High (4-5 events) & $21.8(416)$ & $2.51 * *$ & $(1.4-4.5)$ & 1.72 & $(1.0-3.0)$ & $3.05^{* *}$ & $(1.3-7.0)$ & 0.74 & $(0.4-1.4)$ \\
\hline Very High $(6+$ events) & $7.6(184)$ & $2.04 *$ & $(1.0-4.0)$ & 1.36 & $(0.7-2.6)$ & $2.66^{*}$ & $(1.1-6.6)$ & 1.12 & $(0.5-2.3)$ \\
\hline \multicolumn{10}{|c|}{ W1 Neg. Life Events Prior WTCD } \\
\hline None (Reference) & $56.0(848)$ & 1.00 & & 1.00 & & 1.00 & & 1.00 & \\
\hline One & $27.5(467)$ & 0.76 & $(0.5-1.2)$ & 0.73 & $(0.5-1.2)$ & 1.32 & $(0.7-2.5)$ & 0.77 & $(0.5-1.2)$ \\
\hline 2 or more & $16.5(366)$ & 1.25 & $(0.8-2.0)$ & 1.19 & $(0.7-1.9)$ & 1.66 & $(0.9-3.2)$ & 0.96 & $(0.6-1.5)$ \\
\hline
\end{tabular}


Table 3 (continued)

\begin{tabular}{|c|c|c|c|c|c|c|c|c|c|}
\hline \multirow[t]{3}{*}{$\begin{array}{l}\text { Predictor } \\
\text { variables }\end{array}$} & \multirow{3}{*}{$\begin{array}{l}\text { Total } \\
\text { Year } 1 \\
\%(N)\end{array}$} & \multicolumn{4}{|c|}{ Binge Drinking } & \multirow{2}{*}{\multicolumn{2}{|c|}{$\begin{array}{l}\text { Alcohol Dependence } \\
\text { Past } 2 \text { years } \\
\text { Year } 2\end{array}$}} & \multirow{2}{*}{\multicolumn{2}{|c|}{$\begin{array}{l}\text { Increased } \\
\text { Drinks/Day } \\
\text { Year 1-2 }\end{array}$}} \\
\hline & & \multicolumn{2}{|l|}{ Year 1} & \multicolumn{2}{|l|}{ Year 2} & & & & \\
\hline & & $\overline{\mathrm{OR}}$ & $(95 \% \mathrm{CI})$ & $\overline{\mathrm{OR}}$ & $(95 \% \mathrm{CI})$ & $\overline{\mathrm{OR}}$ & $(95 \% \mathrm{CI})$ & $\overline{\mathrm{OR}}$ & $(95 \% \mathrm{CI})$ \\
\hline \multicolumn{10}{|c|}{ W1 Lifetime Traumatic Events } \\
\hline $\begin{array}{l}0 \text { events } \\
\quad \text { (Reference) }\end{array}$ & $33.6(466)$ & 1.00 & & 1.00 & & 1.00 & & 1.00 & \\
\hline 1 event & $23.4(400)$ & 0.62 & $(0.4-1.1)$ & 0.95 & $(0.6-1.6)$ & 1.04 & $(0.4-2.6)$ & 1.11 & $(0.6-2.0)$ \\
\hline $2-3$ events & $26.7(484)$ & 1.09 & $(0.7-1.8)$ & 1.21 & $(0.7-2.0)$ & 1.83 & $(0.8-4.3)$ & 1.38 & $(0.8-2.3)$ \\
\hline $4+$ events & $16.2(331)$ & 0.87 & $(0.5-1.5)$ & 1.15 & $(0.6-2.0)$ & 1.51 & $(0.6-3.7)$ & 1.52 & $(0.8-2.8)$ \\
\hline \multicolumn{10}{|c|}{ Antisocial behavior history } \\
\hline No (Reference) & $87.8(1435)$ & 1.00 & & 1.00 & & 1.00 & & 1.00 & \\
\hline Yes & $12.2(246)$ & $2.83 * * *$ & $(1.8-4.4)$ & $2.11 * *$ & $(1.3-3.4)$ & 1.66 & $(0.9-3.2)$ & 0.98 & $(0.6-1.7)$ \\
\hline \multicolumn{10}{|l|}{ W1 Social support } \\
\hline Low (Reference) & $34.3(573)$ & 1.00 & & 1.00 & & 1.00 & & 1.00 & \\
\hline Moderate & $36.9(636)$ & 1.07 & $(0.7-1.6)$ & 1.08 & $(0.7-1.7)$ & 1.11 & $(0.6-2.2)$ & 0.99 & $(0.6-1.5)$ \\
\hline High & $28.8(472)$ & 0.87 & $(0.5-1.4)$ & 0.78 & $(0.5-1.3)$ & $2.72 * *$ & $(1.4-5.3)$ & 0.69 & $(0.4-1.2)$ \\
\hline \multicolumn{10}{|l|}{ W1 Self-esteem } \\
\hline Low (Reference) & $32.2(613)$ & 1.00 & & 1.00 & & 1.00 & & 1.00 & \\
\hline Moderate & $25.0(408)$ & 0.81 & $(0.5-1.3)$ & $0.57 *$ & $(0.3-0.9)$ & 0.80 & $(0.4-1.6)$ & 0.80 & $(0.5-1.4)$ \\
\hline High & $42.9(660)$ & 0.78 & $(0.5-1.2)$ & 0.76 & $(0.5-1.2)$ & 0.69 & $(0.4-1.3)$ & 1.34 & $(0.8-2.2)$ \\
\hline \multicolumn{10}{|c|}{ W1 PTSD past year } \\
\hline No (Reference) & $95.9(1561)$ & 1.00 & & 1.00 & & 1.00 & & 1.00 & \\
\hline Yes & $4.1(120)$ & 0.58 & $(0.3-1.2)$ & 0.68 & $(0.3-1.4)$ & 0.78 & $(0.3-2.1)$ & 0.71 & $(0.2-2.1)$ \\
\hline
\end{tabular}

$\mathrm{WTCD}=$ World Trade Center Disaster; $\mathrm{OR}=$ odds ratio; $\mathrm{CI}=$ confidence interval.

a All data are weighted, except the $n$ 's, which are unweighted as discussed in Data and methods.

$* p<0.05$.

$* * p<0.01$.

Analyses examining alcohol dependence between the WTCD and the W2 survey (Table 3) indicated that the educated, males, Latinos, those exposed to more WTCD events, and those with high social support were more likely to meet criteria than respondents who were less educated, female, non-Latino, less exposed to the WTCD, and more isolated. Those who experienced an increase of 2 or more drinks per day in their alcohol consumption between the W1 and W2 surveys were more likely to be younger, male, and Latino compared to older, female, and non-Latino respondents.

\section{Discussion}

The focus of our study was to assess the effects of exposure to recent psychological trauma on alcohol use among a large population sample of adults. We had hypothesized that exposure to WTCD events would be related to both alcohol use and misuse up to 2 years after the WTCD, independent of other risk 
factors, such as demographic characteristics, history of past traumatic exposures, stressful life events, social psychological resources, and history of anti-social behavior. To guide our analytical approach, as noted, we used a general stress process model (Adams \& Boscarino, 2005; Boscarino, 2004; Pearlin, 1989; Thoits, 1995). As was seen, our study generally confirmed our hypotheses. We found that alcohol consumption, binge drinking, and alcohol dependence were associated with exposure to WTCD events, controlling for conventional risk factors for these outcomes.

The multivariate OLS and logistic regression analyses for our 5 alcohol measures indicated an association between WTCD exposure and W1 drinks per month, W2 drinks per month, W1 drinks per day, W1 binge drinking, and W1-W2 alcohol dependence, after controlling for other risk factors. Exposure was not related to W2 drinks per day when drinking, W2 binge drinking, and increases in drinks per day between W1 and W2. In addition, our analyses offered no support for the association between these dependent variables and meeting criteria for PTSD (Tables 2 and 3).

It is now recognized that traumatic stress reactions are complex multi-level phenomena and, as we have suggested above, adverse outcomes following psychological trauma are likely associated with a broad range of outcomes along 3 causal pathways, including biological, psychological, and behavioral (Boscarino, 2004). For example, severe psychological distress can directly result in pathogenesis through alterations in physiologic functions, or indirectly, through altered health behaviors (e.g., alcohol abuse, drug abuse), which result from efforts to reduce aversive psychological states (e.g., anxiety and depression) brought on by PTSD-related psychopathology (e.g., intrusive thoughts and hyper-vigilance). As suggested, it is the latter clinical model that constitutes the core of the alcohol self-medication hypotheses (Epstein et al., 1998; Stewart \& Conrod, 2003).

Recognition of a multi-factorial PTSD model is consistent with the observation that both pharmacotherapy and cognitive-behavioral psychotherapy are reported effective in treating PTSD (Ballenger et al., 2000; Brunello et al., 2001; van der Kolk et al., 1996). In the case of pharmacotherapy, the pathophysiology of PTSD, in part, appears to involve the serotonergic and the noradrenergic systems, hence, drugs known to potentiate these mechanisms have been effective (Brunello et al., 2001). In the case of cognitive-behavioral therapy, this approach has been found effective in reducing PTSD-related symptomotology, by achieving desensitization to stressful stimuli, by increasing control of aversive arousals, by enhancing anxiety management, and by other known behavioral-psychological mechanisms (Boscarino, 2000; Foa, Keane, \& Matthew, 2000; Keane et al., 1985). Although the underlying causal mechanisms may differ for pharmacological versus cognitive-behavioral therapy, the outcomes would be similar - the psychopathology and underlying pathophysiology would be reduced and fewer adverse patient symptoms manifested (Boscarino, 1997), hence, lowering the risk of substance abuse/dependence. Thus, we would expect that as trauma-related symptoms are reduced through treatment, the risk for substance use disorders would also decrease. Recent research has, in fact, confirmed this hypothesis in NYC following the WTCD. For example, it has been reported that NYC adults that received emergency crisis counseling at work shortly after the WTCD, not only had better mental health outcomes, but also better outcomes in terms of binge drinking, alcohol dependence, and alcohol consumption (Boscarino, Adams, \& Figley, 2005).

It should be noted that there are both limitations and strengths associated with our study. First, by omitting individuals without telephones and those who did not speak either English or Spanish, we may have missed highly vulnerable individuals and ethnic groups. Since our sample matched the 2000 Census for NYC, however, these exclusion criteria did not appear to have introduced systematic bias. 
Nevertheless, we are limited in our generalizations about the association between alcohol use and wellbeing beyond English- and Spanish-speaking groups. Only a few studies focus on how the WTCD affected the physical or mental health of immigrant communities or the wide variety of ethnic groups living in NYC (Thiel de Bocanegra \& Brickman, 2004). In addition, all measures of alcohol use, mental health status and well-being were based on self-report. Although there has been progress in assessing individual substance use and mental health status using standardized instruments (Adams et al., 2002; Breslau et al., 1999; Kessler et al., 1994), there continue to be discrepancies between clinician-based and survey-based assessments. Finally, our conclusions are limited by the retrospective nature of the predisaster data, in that we did not have data collected before the disaster. The disaster experience itself may have altered recall related to pre-disaster well-being or substance use. In addition, our data do not allow us to model the changes in alcohol use and well-being over a longer period of time. This limitation, though, is common in disaster research (e.g., Adams et al., 2002; Breslau, Lucia, \& Davis, 2004; Galea et al., 2002). Therefore, we are restricted to making inference with the data we have at the present time.

These limitations should not overshadow the strengths of the study, which include the use of a large random sample representative of NYC, the assessment of well-being using standard scales and measurements, the use of different alcohol measures, and the occurrence of a specific community-wide disaster event. Additional longitudinal research is required to better understand these findings in the future. Nevertheless, our study suggests that there was a possible link between population-level increases in problematic drinking and exposure to a large-scale traumatic event that warrants further research and surveillance.

\section{Acknowledgement}

This study was supported by a grant from the National Institute of Mental Health (Grant \#R01 MH66403) to Dr. Boscarino.

\section{References}

Adams, R. E., \& Boscarino, J. A. (2005). Stress and well-being in the aftermath of the World Trade Center attack: The continuing effects of a community-wide disaster. Journal of Community Psychology, 33, 175-190.

Adams, R. E., Bromet, E. J., Panina, N., Golovakha, E., Goldgaber, D., \& Gluzman, S. (2002). Stress and well-being after the Chornobyl nuclear power plant accident. Psychological Medicine, 32, 143-156.

Allen, J. P., \& Columbus, M. (1995). Assessing Alcohol Problems: A Guide for Clinicians and Researchers. Bethesda, MD: National Institute on Alcohol Abuse and Alcoholism.

American Association for Public Opinion Research. (2000). Standard definitions: Final dispositions of case codes and outcomes rates for surveys. Ann Arbor, MI: Author.

American Psychiatric Association. (1994). Diagnostic and statistical manual of mental disorders (4th ed.). Washington, DC: Author.

Ballenger, J. C., Davidson, J. R. T., Lecrubier, Y., Nutt, D. J., Foa, E. B., Kessler, R. C., et al. (2000). Consensus statement on posttraumatic stress disorder from the International Consensus Group on Anxiety and Depression. Journal of Clinical Psychiatry, 61(Suppl. 5), 60-66.

Bland, S. H., O'Leary, E. S., Farinaro, E., Jossa, F., \& Trevisan, M. (1996). Long-term psychological effects of natural disasters. Psychosomatic Medicine, 58, 18-24. 
Boscarino, J. (1980). Drinking by veterans and non-veterans: A national comparison. Journal of Studies on Alcohol, 41, 954-960.

Boscarino, J. (1981). Current excessive drinking among Vietnam veterans: A comparison with other veterans and non-veterans. International Journal of Social Psychiatry, 27, 204-222.

Boscarino, J. A. (1995). Post-traumatic stress and associated disorders among Vietnam veterans: The significance of combat exposure and social support. Journal of Traumatic Stress, 8, 317-336.

Boscarino, J. A. (1996). Post-traumatic stress disorder, exposure to combat, and lower plasma cortisol among Vietnam veterans: Findings and clinical implications. Journal of Consulting and Clinical Psychology, 64, 191-201.

Boscarino, J. A. (1997). Diseases among men 20 years after exposure to severe stress: Implications for clinical research and medical care. Psychosomatic Medicine, 59, 605-614.

Boscarino, J. A. (2000). Postwar experiences of Vietnam veterans. In G. Fink (Ed.), Encyclopedia of Stress, vol. 3. (pp. 656-662). New York, NY: Academic Press.

Boscarino, J. A. (2004). Association between posttraumatic stress disorder and physical illness: Results and implications from clinical and epidemiologic studies. Annals of the New York Academy of Sciences, 1032, 141-153.

Boscarino, J. A., Adams, R. E., \& Figley, C. R. (2004). Mental health service use 1-year after the World Trade Center disaster: Implications for mental health care. General Hospital Psychiatry, 26, 346-358.

Boscarino, J. A., Adams, R. E., Figley, C. R. (2005). A prospective cohort study of the effectiveness of employer-sponsored crisis interventions after a major disaster. International Journal of Emergency Mental Health, 7, 9-22.

Boscarino, J. A., Figley, C. R., Adams, R. E., Galea, S., Resnick, H., Fleischman, A. R., et al. (2004). Adverse reactions associated with studying persons recently exposed to a mass urban disaster. The Journal of Nervous and Mental Disease, 192, 515-524.

Boscarino, J. A., Galea, S., Adams, R. E., Ahern, J., Resnick, H., \& Vlahov, D. (2004). Mental health service and psychiatric medication use following the terrorist attacks in New York City. Psychiatric Services, 55, 274-283.

Breslau, N., Chilcoat, H. D., Kessler, R. C., \& Davis, G. C. (1999). Previous exposure to trauma and PTSD effects of subsequent trauma: Results from the Detroit area survey of trauma. American Journal of Psychiatry, 156, $902-907$.

Breslau, N., Lucia, V. C., \& Davis, G. C. (2004). Partial PTSD versus full PTSD: An empirical examination of associated impairment. Psychological Medicine, 34, 1205-1214.

Bromet, E. J., Gluzman, S., Schwartz, J. E., \& Goldgaber, D. (2002). Somatic symptoms in women 11 years after the chornobyl accident: Prevalence and risk factors. Environmental Health Perspectives, 110(Suppl. 4), 625-629.

Brunello, N., Davidson, J. R. T., Deahl, M., Kessler, R. C., Mendlewicz, J., Racagni, G., et al. (2001). Posttraumatic stress disorder: Diagnosis and epidemiology, comorbidity and social consequences, biology and treatment. Neuropyschobiology, $43,150-162$.

Caldera, T., Palma, L., Penayo, U., \& Kullgren, G. (2001). Psychological impact of the hurricane Mitch in Nicaragua in a oneyear perspective. Social Psychiatry and Psychiatric Epidemiology, 36, 108-114.

Centers for Disease Control and Prevention. (2002). Deaths in World Trade Center terrorist attacks-New York City. Morbidity and Mortality Weekly Report, 51(Special Issue), 16-18.

Chilcoat, H. D., \& Menard, C. (2003). Epidemiological investigations: Comorbidity of posttraumatic stress disorder and substance use disorder. In P. Ouimette, \& P. J. Brown (Eds.), Trauma and substance abuse: Causes, consequences and treatment of comorbid disorders (pp. 9-28). Washington, DC: American Psychological Publishing.

Cooper, M. L., Russell, M., \& George, W. H. (1988). Coping, expectancies, and alcohol abuse: A test of social learning formulations. Journal of Abnormal Psychology, 97, 218-230.

Cooper, M. L., Russell, M., Skinner, J. B., Frone, M. R., \& Mudar, P. (1992). Stress and alcohol use: Moderating effects of gender, coping, and alcohol expectancies. Journal of Abnormal Psychology, 101, 139-152.

Epstein, J. N., Sanders, B. E., Kilpatrick, D. G., \& Resnick, H. S. (1998). PTSD as a mediator between childhood rape and alcohol use in adult women. Child Abuse and Neglect, 22, 223-234.

Foa, E., Keane, T. M., \& Matthew, J. (Eds.). (2000). Effective Treatment for PTSD. New York, NY: Guilford Press.

Freedy, J. R., Kilpatrick, D. G., \& Resnick, H. S. (1993). Natural disasters and mental health: Theory, assessment, and intervention. Journal of Social Behavior and Personality [Special issue: Handbook of Post-disaster Interventions], 8, 49-103.

Galea, S., Ahern, J., Resnick, H., Kilpatrick, D., Bucuvalas, M., Gold, J., et al. (2002). Psychological sequelae of the September 11 terrorist attacks in New York City. The New England Journal of Medicine, 346, 982-987.

Galea, S., Vlahov, D., Resnick, H., Ahern, J., Susser, E., Gold, J., et al. (2003). Trends in probable posttraumatic stress in New York City after the September 11 terrorist attacks. American Journal of Epidemiology, 158, 514-527. 
Gottheil, E., Druley, K. A., Pashko, S., \& Weinstein, S. P. (1987). Stress and Addiction. New York, NY: Brunner/ Mazel.

Grieger, T. A., Fullerton, C. S., \& Ursano, R. J. (2003). Posttraumatic stress disorder, alcohol use, and perceived safety after the terrorist attack on the Pentagon. Psychiatric Services, 54, 1380-1382.

Groves, R. M., Fowler, F.J, Couper, M. P., Lepkowski, J. M., Singer, E., \& Tourangeau, R. (2004). Survey methodology. New York, NY: Wiley.

Keane, T. M., Zimering, R. T., \& Caddell, J. M. (1985). A behavioral formulation of posttraumatic stress disorder in Vietnam veterans. Behavior Therapist, 8, 9-12.

Kessler, R. C., Little, R. J., \& Groves, R. M. (1995). Advances in strategies for minimizing and adjusting for survey nonresponse. Epidemiologic Reviews, 17, 192-204.

Kessler, R. C., McGonagle, K. A., Zhao, S. Y., Nelson, C. B., Hughes, M., Eshleman, S., et al. (1994). Lifetime and 12-month prevalence of DSM-III-R psychiatric-disorders in the United States-results from the National Comorbidity Survey. Archives of General Psychiatry, 51, 8-19.

Kessler, R. C., Sonnega, A., Bromet, E., \& Hughes, H. (1995). Posttraumatic stress disorder in the national comorbidity survey. Archives of General Psychiatry, 52, 1048-1060.

Kilpatrick, D. G., Ruggiero, K. J., Acierno, R., Saunders, B. E., Resnick, H. S., \& Best, C. L. (2003). Violence and risk of PTSD, major depression, substance abuse/dependence, and comorbidity: Results from the national survey of adolescents. Journal of Consulting and Clinical Psychology, 71, 692-700.

King, M. (1986). At risk drinking among general practice attenders: Validation of the CAGE questionnaire. Psychological Medicine, 16, 213-217.

Linsky, A. S., Colby, J. P., \& Straus, M. A. (1991). Stress, drinking culture, and alcohol problems: A partial test of Bales' theory. In D. J. Pittman, \& H. R. White (Eds.), Society, Culture, and Drinking Patterns Reexamined (pp. 554-575). New Brunswick, NJ: Rutgers Center of Alcohol Studies.

Magruder-Habib, K., Stevens, H. A., \& Alling, W. C. (1993). Relative performance of the MAST, VAST, and CAGE versus DSM-III-R criteria for alcohol dependence. Journal of Clinical Epidemiology, 46, 435-441.

Mecocci, P., Di Torio, A. D., Pezzuto, S., Rinaldi, P., Simonelli, G., Maggio, D., et al. (2000). Impact of the earthquake of September 26, 1997 in Umbria, Italy on the socioenvironmental and psychophysical conditions of an elderly population. Aging (Milano), 12, 281-286.

Naimi, T. S., Brewer, R. D., Mokdad, A., Denny, C., Serdula, M., \& Marks, J. S. (2003). Binge drinking among US adults. JAMA, 289, 70-75.

National Institute on Alcohol Abuse and Alcoholism. (2000). 10 $10^{\text {th }}$ Special Report to Congress on Alcohol and Health. Bethesda, MD: National Institute on Alcohol Abuse and Alcoholism.

Norris, F. H., Friedman, M. J., \& Watson, P. J. (2002). 60,000 disaster victims speak: Part II. Summary and implications of the disaster mental health research. Psychiatry, 65, 240-260.

Ortega, A. N., Rosenheck, R., Alegria, M., \& Desai, R. A. (2000). Acculturation and lifetime risk of psychiatric and substance use disorders among Hispanics. The Journal of Nervous and Mental Disease, 188, 728-735.

Ouimette, P., \& Brown, P. J. (2003). Trauma and substance abuse: Causes, consequences and treatment of co-morbid disorders. Washington, DC: American sychological Publishing.

Pearlin, L. I. (1989). The sociological study of stress. Journal of Health and Social Behavior, 30, 241-256.

Pfefferbaum, B., \& Doughty, D. E. (2001). Increased alcohol use in a treatment sample of Oklahoma City bombing victims. Psychiatry, 64, 296-303.

Resnick, H. S., Kilpatrick, D. G., Dansky, B. S., Saunders, B. E., \& Best, C. (1993). Prevalence of civilian trauma and posttraumatic stress disorder in a representative national sample of women. Journal of Consulting and Clinical Psychology, 61, 984-991.

Rosenberg, M. (1979). Conceiving the Self. New York, NY: Basic Books.

Shalev, A. Y. (1996). Stress versus traumatic stress: From acute homeostatic reactions to chronic psychopathology. In B. A. van der Kolk, \& A. C. McFarlane (Eds.), Traumatic stress: The effects of overwhelming experience on mind, body, and society (pp. 77-101). New York, NY: Guilford Press.

Sherbourne, C. D., \& Stewart, A. L. (1989). The MOS social support survey. Social Science \& Medicine, 32, 705-714.

Stata Corporation. (2001). Stata, version 7.0. College Station, TX: Stata Corporation.

Stewart, S. H. (1996). Alcohol abuse in individuals exposed to trauma: A critical review. Psychological Bulletin, 120, $83-112$. 
Stewart, S. H., \& Conrod, P. J. (2003). Psychosocial models of functional associations between posttraumatic stress disorder and substance use disorder. In P. Ouimette, \& P. J. Brown (Eds.), Trauma and substance abuse: Causes, consequences and treatment of co-morbid disorders (pp. 29-55). Washington, DC: American Psychological Publishing.

Stewart, S. H., Mitchell, T. L., Wright, K. D., \& Loba, P. (2004). The relations of PTSD symptoms to alcohol use and coping drinking in volunteers who responded to the Swissair Flight 111 airline disaster. Journal of Anxiety Disorders, 18, 51-68.

Thiel de Bocanegra, H., \& Brickman, E. (2004). Mental health impact of the World Trade Center attacks on displaced Chinese workers. Journal of Traumatic Stress, 17, 55-62.

Thoits, P. (1995). Stress, coping and social support processes: Where are we? What next? Journal of Health and Social Behavior, 35, 53-79.

Tierney, K. J. (2000). Controversy and consensus in disaster mental health research. Prehospital and Disaster Medicine, 15, $181-187$.

Ursano, R. J., Grieger, T. A., \& McCarroll (1996). Prevention of posttraumatic stress: Consultation, training, and early treatment. In B. A. van der Kolk, A. C. McFarlane, \& L. Weisaeth (Eds.), Traumatic stress: The effects of overwhelming experience on mind, body, and society (pp. 441-462). New York, NY: Guilford Press.

van der Kolk, B. A., McFarlane, A. C., \& van der Hart, O. (1996). A general approach to treatment of posttraumatic stress disorder. In B. A. van der Kolk, A. C. McFarlane, \& L. Weisaeth (Eds.), Traumatic stress: The effects of overwhelming experience on mind, body, and society (pp. 417-440). New York, NY: Guilford Press.

Vlahov, D., Galea, S., Ahern, J., Resnick, H., Boscarino, J. A., Gold, J., et al. (2004). Consumption of cigarettes, alcohol, and marijuana among New York City residents six months after the September 11 terrorist attacks. The American Journal of Drug and Alcohol Abuse, 30, 385-407.

Vlahov, D., Galea, S., Ahern, J., Resnick, H., \& Kilpatrick, D. (2004). Sustained increased consumption of cigarettes, alcohol, and marijuana among Manhattan residents after September 11, 2001. American Journal of Public Health, 94, 253-254.

Vlahov, D., Galea, S., Resnick, H., Ahern, J., Boscarino, J. A., Bucuvalas, M., et al. (2002). Increased use of cigarettes, alcohol, and marijuana among Manhattan, New York residents after the September 11th terrorist attacks. American Journal of Epidemiology, 155, 988-996.

Yehuda, R. (Ed.) (1999). Risk Factors for Posttraumatic Stress Disorder. Washington, DC: American Psychiatric Press, Inc. 